\title{
The Garment Industry in South China
}

Practising Relational Work

Chong Gao and Khun Eng Kuah-Pearce

\section{OpenEdition}

\section{Journals}

\section{Electronic version}

URL: http://journals.openedition.org/chinaperspectives/6781

DOI: 10.4000/chinaperspectives.6781

ISSN: 1996-4617

\section{Publisher}

Centre d'étude français sur la Chine contemporaine

\section{Printed version}

Date of publication: 1 September 2015

Number of pages: 25-32

ISSN: 2070-3449

Electronic reference

Chong Gao and Khun Eng Kuah-Pearce, "The Garment Industry in South China », China Perspectives [Online], 2015/3 | 2015, Online since 01 January 2017, connection on 28 October 2019. URL : http:// journals.openedition.org/chinaperspectives/6781; DOI : 10.4000/chinaperspectives.6781 


\title{
The Garment Industry in South China
}

\author{
Practising Relational Work
}

\author{
CHONG GAO AND KHUN ENG KUAH-PEARCE
}

\begin{abstract}
Since the implementation of China's economic reform and opening-up policy at the end of the 1970s, garment manufacturing for both the domestic and global markets has developed and proliferated quickly in Guangzhou-centred South China. It is believed to be the result of the industrial restructuring of the global apparel commodity chain and a large domestic consumer demand from the Chinese people. Compared with other industries, the garment industry has long been subject to the strong impact of a transitional market economy and, more recently, the increasingly rapid process of marketisation in China. In order to provide a clear sociological conceptualisation of the market economy in the reform era, this paper aims to apply the relational work approach to analysing economic transactions in the garment business, particularly business dealings between garment producers and wholesalers. The focus is on their continued efforts to make appropriate economic arrangements in accordance with specific sets of social relations through continuous relational work. This paper will examine three categories of relational work and the associated economic forms in the making. First, it will explore families and the household economy; second, it will examine relatives and friends and the favour-based economy; and third, it will study strangers and the market economy. Through the use of this relational work framework, this paper will shed light on how the different sets of relational work help us to understand relationships and embeddedness between garment producers and wholesalers in China's rapidly evolving garment economy.
\end{abstract}

KEYWORDS: garment business, social relations, economic transactions, relational work, South China.

\section{Introduction}

T he rise and prosperity of the garment industry in Guangdong has brought Guangzhou (the capital city of Guangdong Province) renown throughout China and the world as a garment collection and distribution centre. The development of garment production in Guangdong in the 1980s, especially in the Pearl River Delta, resulted from the relocation of garment factories from Hong Kong, Taiwan, and other newly industrialising economies in the second half of the 1970s. (1) After World War II, the restructured world economic system and advanced countries chose to concentrate on high technology and on capital-intensive and high-value-added industries. The manufacturing of low technology, labour-intensive, and lowvalue-added products such as garments was transferred to the Asia-Pacific region, South America, and so on. (2) When China adopted its reform and opening policy, clothing production moved further into coastal provinces such as Guangdong and Fujian. In 1976, Guangzhou exported 3.9 million units of garments. (3) By 1992, China had become the largest-volume supplier of textiles and clothing to the U.S. and the European Community. ${ }^{(4)}$ Incomplete statistical data show more than 30,000 garment firms located in Guangdong Province, which produced around 6 billion units of clothing in 2011 (accounted for 23.5\% of China's national garment output). ${ }^{(5)}$ Garment factories in Guangzhou produced about 0.58 billion and 0.54 billion units of clothing in 2010 and 2011 respectively; the export value of garment and accessories was around US\$6 billion-7 billion in 2012 and 2013 respectively. ${ }^{(6)}$

Compared with the prosperity of the garment business, academic research on the garment industry is somewhat "shabby" and scattered. Only a small number of published works are devoted to key issues relating to China's garment industry (including Guangdong Province and Guangzhou). In general, this literature can be roughly divided into three major categories. Some record the spectacular development and economic performance of this industry in the form of historical narratives; some use the global commodity chain approach or organisation theory to analyse the structural and organisational features and competitiveness of China's garment industry; and some investigate labour issues, gender issues, management, and governance in China's garment factories. For example, the China National Garment Association (CNGA, Zhongguo fuzhuang xiehui 中国服装协会) has compiled and published a "China Garment Industry Development Report" each year since 2005 reporting the achievements, current issues, and prospects of the

The authors would like to thank the two anonymous reviewers for their insightful suggestions and comments.

1. Alan Smart and Josephine Smart, "Capitalist Production in a Socialist Society: The Transfer of Manufacturing from Hong Kong to China," in Frances Abrahamer Rothstein and Michael L. Blim (eds), Anthropology and the Global Factory: Studies of the New Industrialization in the Late Twentieth Century, New York, Bergin \& Garvey, 1992, pp. 47-61.

2. Jeffrey Henderson and Richard P. Appelbaum, "Situating the State in the East Asian Development Process," in Richard P. Appelbaum and Jeffrey Henderson (eds), States and Development in the Asian Pacific Rim, Newbury, CA, SAGE Publications, 1992, pp. 1-26.

3. See Guangzhoushi difangzhi bianzuan weiyuanhui (Commission for compiling local historical annals, Guangzhou Municipal Government), Guangzhou shizhi, Juan wu shang (The Chronicle of Guangzhou, Vol. 5, Part 1), Guangzhou, Guangzhou chubanshe, 1998, p. 221.

4. Gary Gereffi, "Commodity Chains and Regional Division of Labor in East Asia," in Eun Mee Kim (ed.), The Four Asian Tigers: Economic Development and the Global Political Economy, San Diego, CA, Academic Press, 1998, p. 107

5. Data from Commission of Economy and Trade, Guangzhou Municipal Government (Guangzhoushi jingji maoyi weiyuanhui), September 2014, email communication.

6. Data from Mrs. Wu Zhenghong, the general secretary of Guangzhou Clothing Trade Association in September 2014. 
industry. ${ }^{(7)} A$ recent study reviews changing market conditions and retailing channels and provides information about the commercial value of the retailing channels of some clothing brands in China. ${ }^{(8)}$ One comprehensive historical research describes changing clothing styles from 1901 to 2000 in China along with the country's dramatic economic, social, and political transformation. ${ }^{(9)}$

Unlike the historical approach, the literature derived from the global commodity chain approach or organisation theory focuses on the dynamic position and unique economic advantages of China's garment industry. The established global commodity chain "consists of sets of interorganisational networks clustered around one commodity or product, linking households, enterprises, and states to one another within the world-economy." (10) In the case of the global apparel commodity chain, the outsourcing practices of Western trading companies, large retailers, and brand holders in the clothing industry over the past decades are often considered the main driving force behind the development of garment production in contemporary China. ${ }^{(11)}$

China's garment industry is also closely related to the Asian apparel commodity chain. At the regional level, some countries or regions have advanced into more strategic positions than latecomers in terms of the division of labour of clothing production, allowing them to move upward in the regional and global apparel commodity chain. For example, in Asia's garment industry, Taiwan cornered the high-end segment of garment production while some Southeast and South Asian countries such as Indonesia, Malaysia, the Philippines, and Sri Lanka produced mid-priced garments. Other Asian countries such as Bangladesh, Cambodia, Laos, and Burma have recently entered the garment production industry. ${ }^{(12)}$ In recent years, China has made a great effort to surpass the manufacturers of high-end clothing. ${ }^{(13)}$ The strategy China has adopted to win a larger market share is the offering of "full-package production." This has become a major threat to other garment exporters. ${ }^{(14)}$ Garment manufacturing enterprises in China "source the materials that go into the garments, they play a role in the design process, they launder the product, and they may ship directly to the retailers." (15)

Chen and Shih argue that because China's garment industry is made up of a large number of small and medium-sized enterprises with limited market experience, management, and operation skills, they do not have sufficient competitiveness in the globalised industry. ${ }^{(16)}$ However, $\mathrm{He}$ and Rayman-Bacchus argue that small enterprises often manage to promote productivity and enhance their competitiveness by positioning themselves in a specific geographical space where they are able to form and join a wellorganised garment cluster that provides synergies in their garment production and trade. ${ }^{(17)}$ The Shaxi garment cluster in Zhongshan City, Guangdong Province, and the Zhili Children's garment cluster in Huzhou City, Zhejiang Province, are examples of clusters that have nurtured many successful small-scale garment enterprises. ${ }^{(18)}$

Other studies focus on labour and worker-related issues in China's garment factories, such as poor working conditions, labour rights, gender inequality, and so on. ${ }^{(19)}$ As in garment factories elsewhere, a large number of unskilled or low-skilled workers from underdeveloped areas and disadvantaged groups (such as migrants from rural villages, laid-off workers, and village girls or women) find jobs in the garment industry, which is a labour-intensive business with low technology. They are located at the lowest end of the global supply chain and suffer from long working hours, low wages, poor labour protection, and other exploitative conditions. ${ }^{(20)}$ In recent years, things have changed somewhat. Pun's field research in two garment factories in Dongguan City, Guangdong Province, shows that workers' lives and working con- ditions have improved with the implementation of company codes of conduct. (21) These studies focusing on the historical development and changes in clothing and clothing production, the global commodity chain, labour relations, and China's positioning of its garment industry in the world economy have enabled researchers to understand the development of the garment production and its global position. This paper focusing on the relational work framework will further extend our understanding of a complex and dynamic relationship within the garment industry.

\section{Theoretical framework and methodology}

When it comes to sociological studies of economic activity in the apparel industry, it is necessary to mention the well-known case study conducted by Brian Uzzi. ${ }^{(22)}$ He lays his theoretical foundation on the debate over embeddedness from Polanyi to Granovetter in economic sociology. Instead of focusing on whether or not and to what extent economic activity is socially

7. See open information on the official website of the CNGA, www.cnga.org.cn/guanggao/ 2013fzbg.asp (accessed on 3 July 2015).

8. Li Hong, Shen Lei, and Zhang Yaping, Zhongguo shichang fuzhuang pinpai jiazhi yanjiu: Qudao tonglu xin geju (Study on the value of brands in China's clothing market: A channel through new patterns), Beijing, Qinghua daxue chubanshe, 2012.

9. Yuan Ze and Hu Yue, Bainian yishang: 20 shiji Zhongguo fuzhuang liubian (A Hundred Years of Costumes: The Transformation of Twentieth Century Chinese Clothes), Beijing, Sanlian shudian, 2010.

10. Gary Gereffi et al., "Introduction: Global Commodity Chains," in Gary Gereffi and Miguel Korzeniewicz (eds), Commodity Chains and Global Capitalism, Westport, CT, Greenwood Press, 1994, p.

11. Richard P.Appelbaum and Gary Gereffi, "Power and Profits in the Apparel Commodity Chain," art. cit., pp. 42-62; Gary Gereffi, "The Organization of Buyer-Driven Global Commodity Chains: How U.S. Retailers Shape Overseas Production Networks," in Gary Gereffi and Miguel Korzeniewicz (eds), Commodity Chains and Global Capitalism, op. cit., pp. 95-122.

12. Rajah Rasiah and Rene E. Ofreneo, "Introduction: The Dynamics of Textile and Garment Manufacturing in Asia," Journal of Contemporary Asia, Vol. 39, No. 4, 2009, pp. 501-511.

13. Gary Gereffi, "Commodity Chains and Regional Division of Labor in East Asia," art. cit., pp. 100101.

14. Wai Kit Choi and David A. Smith, "China and the Global Apparel Commodity Chain," Peace Review: A Journal of Social Justice, No. 22, 2010, p. 421; Frances Abrahamer Rothstein, "Flexibility for Whom?: Small-Scale Garment Manufacturing in Rural Mexico," in Alan Smart and Josephine Smart (eds), Petty Capitalists and Globalization: Flexibility, Entrepreneurship, and Economic Development, Albany, Sate University of New York Press, 2005, pp. 67-81; Markus Hassler, "The Global Clothing Production System: Commodity Chains and Business Networks," in Global Networks, Vol. 3, No. 4, 2003, pp. 513-531.

15. Wai Kit Choi and David A. Smith, "China and the Global Apparel Commodity Chain," art. cit., p. 421.

16. Chien-Hsun Chen and Hui-Tzu Shih, "The Impact of WTO Accession on the Chinese Garment Industry," Journal of Fashion Marketing and Management: An International Journal, Vol. 8, No. 2, 2004, pp. 221-229.

17. Zheng He and Lez Rayman-Bacchus, "Cluster Network and Innovation under Transitional Economies: An Empirical Study of the Shaxi Garment Cluster," Chinese Management Studies, Vol. 4, No. 4, 2010, pp. 360-384

18. For the Shaxi case, see Zheng He and Lez Rayman-Bacchus, "Cluster Network and Innovation under Transitional Economies: An Empirical Study of the Shaxi Garment Cluster," art. cit:; for Zhili case, see Huang Zuhui et al.," "Sticky Factors in the Industrial Relocation of a Cluster: A Case Study of Zhili Children's Garments Cluster in China," The Social Science Journal, Vol. 48, No. 3, 2011, pp. 560-565.

19. Anita Chan, "Recent Trends in Chinese Labour Issues - Signs of Change," China Perspectives, No. 57, 2005, pp. 23-32.

20. Zhuang Yuxi et al., Shui Maidiao Laogong Quanli?: Quanqiu gongyinglian de caigou moshi yu gongren shenghuo (Who is selling out labour rights?: Clobal supply chain buying patterns and workers' livelihood), Hong Kong, Leshihui, 2004; Anita Chan and Kaxton Siu, "Analyzing Exploitation: The Mechanisms Underpinning Low Wages and Excessive Overtime in Chinese Export Factories," Critical Asian Studies, Vol. 42, No. 2, 2010, pp. 167-190.

21. Pun Ngai, "Clobal Production, Company Codes of Conduct, and Labor Conditions in China: A Case Study of Two Factories," The China Journal, No. 54, 2005, pp. 101-113.

22. Brian Uzzi, "Social Structure and Competition in Interfirm Networks: The Paradox of Embeddedness," Administrative Science Quarterly, Vol. 42, No.1, 1997, pp. 35-67; Brian Uzzi, "The Sources and Consequences of Embeddedness for the Economic Performance of Organizations: The Network Effect," American Sociological Review, Vol. 61, No .4, 1996, pp. 674-698. 
embedded, (23) his study focuses on how economic actions are embedded into social networks and on the multiple effects of the level of embeddedness. Using both ethnographic and statistical data regarding apparel firms in New York, Uzzi found that garment firms with some embedded ties enjoyed extra benefits in terms of trustworthiness, access to valuable information, and joint problem-solving arrangements. ${ }^{(24)}$ This finding echoed other studies on the global commodity chain - that "networks are situationally specific, socially constructed, and locally integrated, underscoring the social embeddedness of economic organization." (25) His study also revealed that the positive effect of embeddedness is not unconditional. To him, "embeddedness, however, yields positive returns only up to a threshold point. Once this threshold point is crossed, returns from embeddedness become negative." (26) Uzzi's arguments indicate that in theory the marketbased economy is impersonal and separated from the social world, but that in reality it is embedded/constrained by social networks. His ethnographic account of the networks of garment manufacturers and contractors emphasised that repeated transactions help to nurture a sense of friendship and mutual commitment and establish lasting business and friendship relations. To him, this kind of embeddedness shows economy transactions as something embedded in the social network, but without taking into consideration the need to differentiate social connections from associated norms and obligations.

Unlike Uzzi's informants, the majority of our research subjects are businesspeople who were connected by pre-existing relationships before they entered the business world. From the day they left their hometowns to seek job and/or business opportunities for survival, the economy (in their words, subsistence or "having a bowl of rice to eat") became an integral part of their social life. In this regard, we argue that the concept of relational work is more applicable in our study of this group of businesspeople working in the garment industry. Unlike the network embeddedness perspective that sees the economy and society as two separate spheres, relational work "is grounded in connected lives, and interactionally sustains the mutual constitution and elaboration of the economic and the social spheres." (27) This approach begins with the nature of social relations and suggests that particular social connections inherently accord with certain socially legitimate economic exchanges. As such, the concept of relational work "posits that in all areas of economic life people are creating, maintaining, symbolizing, and transforming meaningful social relations." (28) In this sense, four major tasks are undertaken in a certain type of well-defined economic transaction: 1) clarifying the nature of the social connections involved; 2) formulating proper economic arrangements in accordance with that type of social connection; 3) choosing a socially legitimate medium (or media) of exchange for that type of social connection and economic transaction; 4) arriving at a social consensus on the negotiated meanings and economic arrangements in line with the connection engaged. Zelizer refers to this process of economy formation as a "relational package." (29) The future study of economic activities should therefore focus on the distinctive social connections involved, the transactions conveying goods and services, the medium/media of exchange specified for certain type of transactions, and the negotiated meanings in the course of matching social connections and economic arrangements. ${ }^{(30)}$

Due to length limitations, this paper does not intend to provide a full review of all of the discussions and arguments related to embeddedness and relational work. In short, the key difference between the two approaches is that the embeddedness approach begins with an impersonal market-based economy, while relational work starts out from differentiated social connections. The next step following in the embeddedness approach is to explore how market economy is embedded in a social network and the possible outcomes of embeddedness. In the relational work approach, economic arrangements should be purposefully formulated and constituted to fit into a certain type of social relation. (31) That is to say, a socially legitimate and constructed economy will be aligned with specific social relations. In theory, the market-based economy is viewed as a socially constructed economic form for strangers, which is commonly practiced between unknown market participants such as isolated buyers and sellers. For the same reason, a household economy will be deliberately created and practiced for the most intimate family relations. As a result, economic arrangements and forms should inherently conform to the ground rules of particular social relations so it will not be necessary to make them become embedded once again. Relational work therefore "provides a microfoundation for understanding how economic exchange is accomplished, which effectively avoids the undersocialized and oversocialized views of economic behavior." (32) Moreover, the economies generated from negotiated relations range from household economy, favour exchange, and commercial transaction among relatives or friends, informal economy, gift economy, and donation, to purely self-interested market economy. ${ }^{(33)}$

Inspired by insights from relational work studies, this paper aims to engage in a close examination of economic transactions detected in our field research in Guangzhou's garment industry. In fact, participants in the wholesale market include stall-keepers, buyers from different places, managers of the market, market regulators, manufacturers (garment production service providers), logistics service providers, and so on. It is impractical to cover all the kinds of economic transactions conducted by so many actors. As such, this study will concentrate on the major types of transactions between manufacturers and wholesalers in the garment wholesale business. The focus is on the negotiation of their social connections (families, relatives, friends, or strangers) and the formation of economic forms in line with particular social relations.

Ethnographic fieldwork is useful in investigating the dynamic and complicated negotiating process because it enables access to first-hand data concerning the interactions of people and the actual exercising of social relations and business operations in the real world. The data used in this paper were collected from ethnographic fieldwork and repeated visits from 2002 to 2003 (including 13 months in factories and 41 interviews with factory owners), in 2007 (two months in a wholesale market and 25 interviews with stall-keepers), and 2014 (an interview with the senior manager of the

23. Mark Granovetter, "Economic Action and Social Structure: The Problem of Embeddedness," The American Journal of Sociology, Vol. 91, No. 3, pp. 481-510.

24. Brian Uzzi, "The Sources and Consequences of Embeddedness for the Economic Performance of Organizations: The Network Effect," art. cit.

25. Gary Gereffi et al., "Introduction: Global Commodity Chains," art. cit., p. 2.

26. Brian Uzzi, "The Sources and Consequences of Embeddedness for the Economic Performance of Organizations: The Network Effect," art. cit., p. 694.

27. Nina Bandelj, "Relational Work and Economic Sociology," Politics \& Society, Vol. 40, No. 2, 2012, p. 192.

28. Viviana Zelizer, "How I became a Relational Economic Sociologist and What Does that Mean?," Politics \& Society, Vol. 40, №. 2, 2012, p. 149.

29. Ibid., p. 151.

30. Ibid., pp. 151-152.

31. Fred Block, "Relational Work in Market Economies: Introduction," Politics \& Society, Vol. 40, No. 2, 2012, pp. 136-137.

32. Nina Bandelj, "Relational Work and Economic Sociology," art. cit., p. 177.

33. Fred Block, "Relational Work in Market Economies: Introduction," art. cit., pp. 141-143. 


\section{Diagram 1 - Clothing commodity chain in Guangzhou}

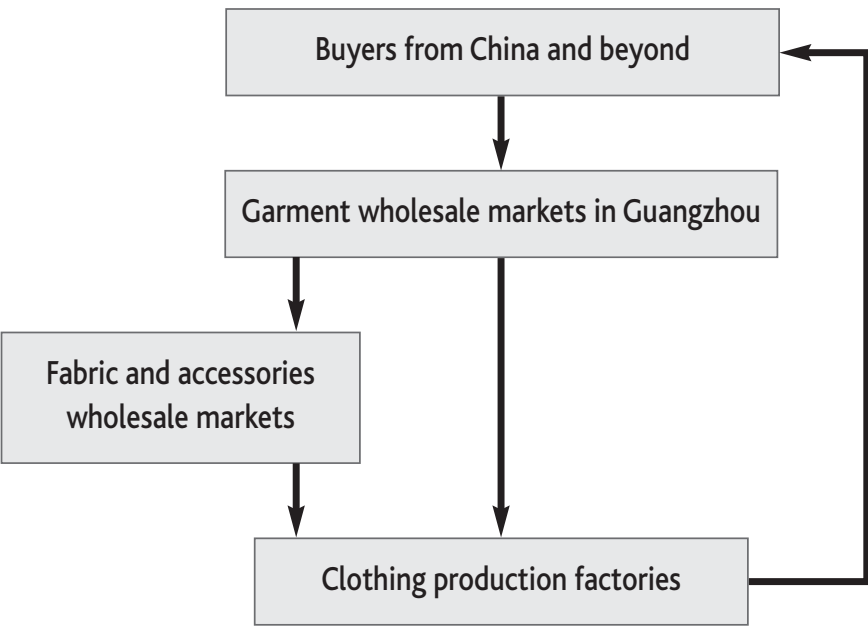

Baima Garment Wholesale Market). In order to learn more about the overall situation of Guangzhou's garment industry, we visited the Guangzhou Clothing Trade Association (Guangzhou fuzhuang hangye xiehui 广州服装 行业协会) and Guangzhou's leading wholesale market, the Baima Garment Wholesale Market (Guangzhou baima fuzhang shichang 广州白马服装市场) in September 2014. Our informants included factory proprietors who owned and ran small and medium-sized garment factories in suburban Guangzhou, stall-keepers who ran wholesale businesses in the garment wholesale markets, the general secretary of the Guangzhou Clothing Trade Association, and a senior manager of the Baima Garment Wholesale Market. The business operators contacted at the fieldwork site were often non-local grass-roots petty entrepreneurs with limited education, so they usually started their business by learning from experience and street wisdom. Most of them had some years of work experience in the apparel industry before they took the risk of starting their own businesses to improve their lives. For them, working for others and entrepreneurship are closely integrated in their daily practice of subsistence.

During our fieldwork, we engaged in participant observation and indepth interviews among the informants to gather on-the-ground information about their business operations and social interactions. General data on the day-to-day operations of garment production and business transactions were collected through participant observation. Taking a seat in garment factories and in the stalls of garment wholesale markets offered opportunities to closely observe what actually happened there. Participant observation was often conducted on the shop floor of garment factories, their residential quarters (often part of the shop floor), and the garment wholesale markets. In addition, semi-structured interviews were conducted among factory proprietors and stall-keepers. In total, 66 businesspersons were interviewed. The interviews centred on their personal understanding of social connections and proper behaviour in business, as well as their interactions in diverse aspects of their business operations. When conditions allowed, we also engaged in casual conversations with their business partners, customers, employees, relatives, and friends to cross-check information. The latest visit in September 2014 found the daily business operations in the garment wholesale market similar to what we observed during our fieldwork in 2007. What really changed was the proliferation of fashion apparel and the superior quality of the clothing. This was confirmed in an interview of Mrs. Zhang, one of the top managers of the Baima Garment Wholesale Market. Although Mrs. Zhang noted that the upgrading of design and quality did not have a major impact on transactions between manufacturers and stall-keepers, we needed more interview data to cross-check this information. This is one of the limitations of this study.

\section{The wholesale market and market transactions between strangers}

Guangzhou's garment industry adopts a "full-package production" pattern to meet the demands of both the international and domestic markets. The unique feature of the organisation of the garment business here is that it centres on dozens of wholesale markets in Guangzhou City. ${ }^{(34)}$ There are reportedly more than 100 large-scale garment wholesale markets congregated in four areas of Guangzhou: Liuhua District (Liuhua diqu 流花地区), with more than 40 wholesale markets (the Baima 白马 Wholesale Market being representative), some 12,000 stall-keepers, and an annual transaction value of about 40 billion yuan; Shahe District (Shahe diqu 沙河地区) with more than ten wholesale markets (the Shadong youli 沙东有利 garment town being the largest), some 4,000 stall-keepers, and an annual transaction value of more than 3 billion yuan; and the area of Shisanhang Road (Shisanhang lu 十三行路) and Heping Road (Heping lu 和平路), with about ten wholesale markets (the Hongbiantian 红遍天 garment trading centre being the most important), some 1,000 stall-keepers, and an annual transaction value of about 1 billion yuan. ${ }^{(35)}$ The flourishing garment trade and the establishment of these large-scale wholesale garment markets in Guangzhou have led to a great demand for small and medium-sized garment factories. Stall-keepers in the wholesale market usually require garment manufacturers to offer flexible production in order to avoid overstocking. Speed is thus essential to garment production: garment manufacturers are often given less than 24 hours to produce a specified quantity of garments. It is not uncommon for buyers to demand speedy delivery in order to avoid overstocking. Large-scale garment factories are unwilling to accept such orders, but small and medium-sized garment factories will take on such production with short deadlines.

The general flow of garment production and transactions in Guangzhou is carried out in the following way: the process begins in the booths, stalls, or showrooms in the wholesale market, where buyers from different parts of the world make deals with stall-keepers in the morning. With the requirements and specifications of buyers in hand, the stall-keepers go to the cloth and accessories wholesale markets to purchase the raw materials needed for clothing production after lunch. The raw materials are then sent to their own factory or a subcontracted factory for processing and manufacturing from dawn to early morning the next day. The finished made-to-order garments will be delivered to the wholesale market or a designated location. The composition of the business is demonstrated in Diagram 1.

It is not difficult to find that the three most important elements of the business transactions are negotiating the price for the work, quality control, and timely delivery. If contracts are made among unknown actors and governed by pure market principles, stall-keepers and factory owners without pre-existing connections will maximise their own economic interests

34. For a detailed description of Guangzhou's garment industry, see Gao Chong, The Making of Migrant Entrepreneurs in Contemporary China: An Ethnographic Study of Garment Producers in Suburban Guangzhou, unpublished PhD thesis, Department of Sociology, the University of Hong Kong, 2006.

35. Data from Mrs. Wu Zhenghong, the general secretary of the Guangzhou Clothing Trade Association in September 2014 
through varied price bargaining. For the wholesalers who must send work to the garment factories, self-interested rationality drives them to find a contractor who is willing to accept an order at a low price (the lower the better, in some sense). On the other hand, manufacturers rely on the payoff from their manufacturing services to maintain their financial stability, so they want to charge more. In order to arrive at a mutually acceptable market price, the two parties often drive a hard bargain over each deal.

Based on stories from our informants, transactions with unknown businesspeople are usually conducted in two ways. In the first method, the stall-keeper who gets orders in the wholesale market may buy the fabric, accessories, and other materials needed and then deliver them to the garment cluster housing hundreds of small-scale factories. He/she may read all kinds of signboards and advertisements on the wall and decide to knock at the door of a factory that seems likely to undertake the job. If the factory owner happens to be available, the two parties can discuss the trading terms immediately. If the result is unsatisfactory, the stall-keeper will move on, repeating the negotiation process. Once an agreement is reached, the stall-keeper may leave the materials at the factory, pay a deposit, and await the completed garments. In the second and commonly used method, factory owners get in touch with unknown stall-keepers by walking around the wholesale markets and distributing their name cards, which include key information about the factory such as business type, expertise, business philosophy, and contact information. If they receive inquiries, they may discuss transaction details over the phone and invite interested parties to visit the factory. Although most of our informants admitted that they knew how to use the above methods to conduct business relations with unknown clients, they tended to regard such methods as a last resort. Two informants with real experience with these methods noted that they are time-consuming and not effective.

The biggest problem arising in conducting business with strangers is that neither quality control nor timely delivery are guaranteed. Payment for manufacturing services can only ensure that the garments will be made; monitoring of the production process, satisfactory quality, and timely delivery are often regarded as extra services wholesalers should buy. When manufacturers and wholesalers are strangers conducting a transaction for the first time, both parties believe that the connection is largely built on economic interests, and it is reasonable to let money speak during the process of transaction and interaction. If the wholesaler is unwilling to pay extra for quality and timely delivery, he/she should not have such high expectations of either.

\section{Relational work and transactions among relatives and friends}

As discussed above, only a few of the informants we interviewed actually attempted to do business with unknown people in the market. Most factory owners became acquainted with at least one client through their social network before they opened their factories. For stall-keepers, it usually took an emergency situation for them to approach an unfamiliar garment factory, especially in the peak season. Considering the quality of the product, delivery time, production costs, favours in handling emergency orders, and so on, both stall-keepers and factory owners tend to maintain stable and longterm collaborative relationships.

Similar to the interactions between OEMs (Original Equipment Manufacturers) and their suppliers in the metal manufacturing industries in the U.S., Guangzhou's garment business operates under a social situation in which the roles of business operators, the terms of transactions, and the social norms governing transactions are ambiguous. ${ }^{(36)}$.Some social relations and logics of action "are - or are not - intermingled and recombined" into the process of business, so it is necessary "to identify the ways in which actors combine social ties, transactions, and media into relational packages, as well as the ways they attach and contest the meanings that can be attached to those 'relational packages'." (37) In terms of Guangzhou's garment industry, the commonly used social ties are typically generalised under the label of "relatives and friends" (qinqi pengyou 亲戚朋友). In fact, the term "relatives and friends" covers different types of pre-existing social connections, ranging from kinship relations and hometown-fellow relations to former employer-employee relations. Given the common practice of economic cooperation and favours among relatives and friends in Chinese society, it is not surprising to find that these relations have become an integral part of transactions in the garment industry. The variety of relatives and friends makes it possible to find business partners within this kind of social network.

Some businesspeople may turn to relatives for help when they cannot manage to run both wholesale and production businesses within their own families. The uneven distribution of business volume from day to day, the dramatic rise and fall of business in the rush and slow seasons, and the rapid fluctuation of production costs make it difficult to build up reliable partnership relations among wholesalers and manufacturers. Kinship provides a foundation for them to establish mutual support and win-win relations in the course of business. Miss Huang's uncle runs a clothing production factory in suburban Guangzhou but often encounters difficulties in finding orders and in cooperating with stall-keepers with orders in hand. When Miss Huang graduated from high school and was unwilling to continue her studies, her uncle decided to provide start-up funding for her to launch her own garment wholesale business in New China Market (Xin Zhongguo dasha 新中国大厦). The condition was that she should forward the orders she received from buyers to her uncle's factory. She fully accepts this arrangement, as she feels it is difficult and very troublesome to find a suitable manufacturer. "I come and stay here for only a few months. I do not know how to look for a garment factory at all. There is a good relationship between my family and my uncle. I trust him." She usually visits her uncle and his factory when the wholesale market is closed in the afternoon. In this way, home visits and business transactions are well integrated among relatives.

Some factory owners also depend on relatives to introduce clients. For example, Mr. Lu is Mr. Dai's cousin. When Mr. Lu began to run his own garment factory in November 2002, Mr. Dai had already been operating his factory for about seven months and had developed business relationships with three regular clients. Considering their kinship relationship, Mr. Dai introduced one of his clients to his cousin. This client, whose business size is very limited, had no great effect on the economic performance of Mr. Dai's factory, but could help his cousin secure a crucial source of orders and income at the start-up stage.

Kinship relations can also be extended into the construction of a business circle. For instance, Mr. Dong established his garment factory in 1998 and cultivated good connections with many clients. When relatives, such as his cousin and his brother-in-law, opened garment factories later, they turned

36. Josh Whitford, "Waltzing, Relational Work, and the Construction (or not) of Collaboration in Manufacturing Industries," Politics \& Society, Vol. 40, No. 2, 2012, pp. 249-271.

37. Ibid., p. 255. 
to Mr. Dong for help and relied on him to introduce clients. For Mr. Dong sharing clients and orders within a closed business circle is very important for an individual factory. The production capacity of an individual factory and orders from clients are often imperfectly matched. If the factory can build an alliance with other trusted factories, they can help each other by having one bring in the order and another produce the garments. In this way, each factory helps the others maintain the production process during the slow season and "digest" the heavy workload during the rush season. Punctual production and delivery may burnish the reputation of each factory in the circle and enable it to win more orders. In order to enhance trustworthiness and minimise the free-rider phenomenon, business circles of this kind should be closed, and kinship relations can provide a suitable platform to form such a circle. The concepts of mutual aid among relatives and loyalty to kinsmen are intermingled with mutual support in the business world. Apart from relatives, the hometown-fellow relationship is also mobilised to gain access to clients and orders. When an individual plans to establish a garment factory or run a stall in the wholesale market, he/she is likely to find that pre-existing hometown-fellowship can bring in clients for business transactions. The shared feeling and place-identity facilitates business cooperation among a group of people who come from the same locality or region. For instance, when Mr. Chen decided to start his garment factory in 2001, he purposely located the factory in an industrial building housing four other factories owned by fellow natives of Hubei Province (Hubei sheng 湖北省). Once he became acquainted with the factory owners in the same building by means of their shared hometown connection and other social interactions, they often gave him work.

Sometimes kinship relations and hometown-fellow relations are not available (or useful), and in this case, a specific connection established through employment or common work experience can be a substitute. As employers, employees, and co-workers usually have different place of origin and economic interests, it is not easy for them to build up the trust and collaborative connection required for future collaboration in business. Only a few exceptions were found during our fieldwork. The collaborative connection between Mr. Wan and Mrs. Du offers a case of this kind. Mr. Wan had more than 20 years' experience in the garment industry, including working in garment factories and running his own factory in his native Anhui Province (Anhui sheng 安徽省). Mrs. Du was a divorced woman from Shenyang City, Liaoning Province (Liaoning sheng Shenyang shi 辽宁省沈阳市), who ran a garment factory and wholesale stall in Guangzhou. When Mr.Wu came to Guangzhou seeking work after his business failed, he was hired as manager of the factory owned by Mrs. Du. Unfortunately, Mrs. Du lost money in both her wholesaling and manufacturing businesses half a year later. In order to cope with her business difficulties, she decided to sell the factory and sub-contract out the production work. As Mrs. Du had no relatives or hometown fellows available to open a factory in Guangzhou, she suggested that Mr. Wan do this. Mr. Wan took this opportunity to start up a new factory. When Mrs. Du received orders, she forwarded them to Mr. Wan's factory. In this manner, the former employment connection between them was converted into a business partnership.

In addition, former co-worker relations can be employed to create client relations. Mr. Zheng had worked in garment factories in Guangzhou for around 20 years when he opened his own clothing factory. Hearing that some of his former co-workers operated garment wholesale businesses, he visited different garment wholesale markets and went through almost all the stalls and actually found two of his former co-workers running stalls in the Shisanhang + 三行 wholesale market. He visited them and gave them information about his factory and naturally enquired about whether they could give him some work. Ultimately, one of his former co-workers promised to send orders to his factory. Mr. Zheng explains, "He knows of my expertise in garment production from working in the same factory. I knew how to operate and repair all the sewing machines in the factory, and all the others admired me." A history of working together facilitates mutual understanding and lays a foundation for business relations. Relational work may be unintentional, as the actors merely interact and play their roles in the current stage without being able to predict what will happen in the future. What is important is to make use of different ways to sustain relations and remain well connected.

Various strategies are employed to maintain business relations with clients. ${ }^{(38)}$ The first is to use money as a social instrument to consolidate interpersonal connection. It is common for businesspeople to give larger amounts of money as gifts to friends in their business circle. Here, giving money in the form of a "red envelope" (hongbao 红包) has both sociocultural and economic implications. In China, money in a red envelope is used as a gift on various occasions, such as weddings, birthdays, or traditional festivals (in particular to children and dependent elders at the Lunar New Year). ${ }^{(39)}$ In a cultural sense, the amount of cash in the "red envelope" depends on the relative generational level, age, and social distance, ${ }^{(40)}$ but some informants noted that they would give a double amount if the recipient was their existing or potential client. The extra money often indicated a strong inclination to build up or enhance their connection with the client. Secondly, playing mah-jong helps to maintain relations with clients. As one of the major entertainments among businesspeople in the clothing industry, playing mah-jong is also employed to foster friendships between factory owners and their clients. It is not unusual to find a mah-jong table in the office of a factory boss. Some of our informal interviews during fieldwork were conducted beside a mah-jong table. One day when a fieldworker visited Mr. Xiao, he was playing mah-jong with a client from northeast China in his office. Mr. Xiao arranged a seat for the fieldworker beside the mahjong table and continued his game as usual. The client was happy because he won from time to time. When Mr. Xiao's wife told the client that the pants he ordered were finished and asked him to have a look, he was reluctant to leave. "It is not necessary to check. I trust you!" he said. The interview with Mr. Xiao indicated that he accompanied the client to play mah-jong or to drink and eat in restaurants from time to time. He believed that it was his responsibility to maintain a strong connection and cultivate friendship with the client.

Another factory owner, Mr. Guo, often invites clients out to eat in restaurants, to have casual chats, or for entertainment or mah-jong. He also sends clients gifts at festivals. "As we are friends, I understand their requirements and even know how much they earn. This year, one of my friends cooperated with me for more than 40 days. I realised that he didn't make money at all, so I waived part of his manufacturing service charge. It was about 40,000 yuan. If he has some lucrative orders in the future, he'll feel obliged to place them with my factory." This shows how social interactions in daily life are merged with business transactions. Business operators have to consider friendship, feeling, and favours received in business decision-making.

Thirdly, offering sexual services is mentioned as a way to maintain a con-

38. Mayfair Mei-hui Yang, Gifts, Favors, and Banquets: The Art of Social Relationships in China, Ithaca, New York, Cornell University Press, 1994, pp. 64-65.

39. Hill Gates, "Money for the Gods," Modern China, Vol. 13, No. 3, 1987, p. 263.

40. Charles Stafford, The Roads of Chinese Childhood: Learning and Identification in Angang, Cambridge, Cambridge University Press, 1995, pp. 79-111. 
nection with clients. The provision of women's sexual services has become a "new form of guanxi practice emerging in the reform period which is, not surprisingly, found in the business world." (41) In Chinese parlance, "massage parlour" or "hair salon" (falang 发廊) is often an alias for "brothel," as many female employees offer various sexual services. ${ }^{(42)}$ Entertainment centres with massage services are located in clusters of clothing factories. There are also dozens of hair salons without barbers but with young female employees. Enjoying sexual services with a group of "business friends" in a massage parlour or hair salon is a common topic of discussion among male business proprietors. At least two factory owners admitted to doing it.

In sum, relatives and friends have their own social implications and economic significance for this group of businesspeople in Guangzhou's garment industry. Their social awareness of the obligations associated with different types of relatives and friends often obliges them to do favours for particular relatives or friends. Under these conditions, they often attempt to meet the expectations of relatives or friends and respect the economic interests of both sides. In most cases, the relatives and friends connection provides a broad space to practice a variety of relational work because it constitutes a major part of social life and economic life. Different interests, goods, and services can be exchanged in an appropriate manner within networks of relatives and friends.

\section{Relational work and transactions within the family}

For some businesspeople, the ideal pattern is to own and run both a clothing production factory and a stall in a garment wholesale market. Family members take on different duties in the business depending on their own competence and expertise. The typical division of labour is that the wife supervises the stall in the wholesale market and the husband spends more time running the factory. Fieldwork data also shows that some adult sons may assist their mothers in handling transactions at the wholesale market stall. The popular explanation for this kind of arrangement is that women are more capable in communicating with clients and more experienced in bargaining over prices. Their daily routine is to open the indoor stall in the early morning and stay there until around four o'clock. On the other hand, men are considered better suited to managing the production process, maintaining order on the shop floor, and dealing with cadres or staff from various levels of the bureaucracy.

Apart from economic and instrumental considerations, the family obligations associated with family members are also combined with the business process. When the husband can free himself from the daily management of the factory, he visits the family's wholesale stall and gives his wife help and support. Mr. He puts it simply: "We are in the same family and don't have a clear division of labour." As his son and daughter are studying in middle school in their hometown (Xiaogan City, Hubei Province Hubei sheng Xiaogan shi 湖北省孝感市) and are not available to join the business, he and his wife run a clothing factory in suburban Guangzhou and a stall in the Shahe Wholesale Market by themselves. They usually hire a cargo van to deliver pre-made garments to their stall at around four or five o'clock in the morning. Mr. He often has breakfast with friends at a food stall next to the wholesale market while his wife does business in the stall. Then he goes back to his factory, where his bedroom is located, and gets some sleep. His wife informs him of the amount of clothing sold and the orders received at around two or three o'clock in the afternoon. Then he does a rough calcu- lation of how much fabric and related accessories are needed and purchases them from the fabric and accessories wholesale market. This kind of collaboration is taken for granted by both of them in their day-to-day business operations.

Based on a strong sense of family identity, family members often work closely to expand their business. Mrs. Tang and her husband, Mr. Xiao, also run both a stall and a factory in the garment industry, but what makes their case interesting is that their stall is operated in Guangzhou while the factory is located hundreds of kilometres away in Yulin City in the Guangxi Zhuang Autonomous Region (Guangxi Zhuangzu zizhiqu Yulin shi 广西壮族自治区 玉林市). Mrs. Tang began her wholesale business in Guangzhou in the 1990s when her daughter and two sons were very young. Meanwhile, her husband opened and ran a clothing factory to produce goods for the stall. Mrs. Tang explains that they do everything to maximise profits and provide a better future for the family. "We were very poor at that time, so we had to make money to support our family. Sometimes my husband had to take a longdistance bus to deliver just two hundred units of garments to Guangzhou overnight. It was small business that others can easily overlook, but we still tried to grasp every opportunity for more profit." When her two sons graduated from college, they chose to move to Guangzhou and help their mother. When they were interviewed, they noted that it was time for them to relieve their parents' burden and make some repayment and contribution to the family. "We witnessed the hardship of our family and the diligence of our mother and father. Now that we're grown-up and capable of taking jobs, this is what we should do."

The pursuit of family well-being, fulfilment of family duties, and mutual support among family members transform the meaning of business into family commitment. An individual's contribution to the business is equated with his/her caring and love for the family. In this regard, relational work among family members makes the business an integral part of family life. Moreover, family commitment may promote economic efficiency and enhance the business's chance for survival and success.

Whether business operators like it or not, pre-existing relations such as family relations, kinship, and hometown-fellow relations, as well as former employer-employee or co-worker relations, are intermingled and recombined into day-to-day business operations. Some social skills of interaction and connection are purposely utilised in the daily life and business operations of businesspeople. It should be noted that family and kinship relations do not always have a positive effect on economic transactions. When a mismatch between kinship/family relations and business transaction occurs, the relationship is likely to be damaged to some degree, and disputes and conflicts may emerge. During our fieldwork and interviews, a few informants admitted the occurrence of disputes or conflicts under some conditions, but they were usually unwilling to talk about these negative issues in great detail.

\section{Conclusion}

In the twenty-first century, China will continue to be a primary garment producer on the global stage, especially as the Chinese economy continues to open up to the world's challenges. From the historical perspective, it is easy to see that the rise of the garment industry (Western-style clothing)

41. Mayfair Mei-hui Yang, "The Resilience of Guanxi and its New Developments: A Critique of Some New Guanxi Scholarship," The China Quarterly, No. 170, 2002, p. 466.

42. Gregory Eliyu Guldin, What's a Peasant to Do? Village Becoming Town in Southern China, Boulder, CO, Westview Press, 2001, pp. 213-215. 
in Guangzhou is largely related to the new division of labour in the global clothing commodity chain since the 1980s. Understanding its success goes beyond existing theories of structural changes, competitive advantages, and labour issues. Increasingly, the social and human factors that influence economic transactions need to be explored. Our paper is an attempt to address this gap. In our case study, most stall-keepers and factory owners were interconnected through pre-existing relative, friend, or family relations before they entered the business.

By framing this study using the concept of relational work, we argued that business transactions between wholesale market stall-keepers and factory proprietors result from continuous relational work. When a stall-keeper or a factory owner chooses to do business with a client without a pre-existing connection, he/she will drive a hard bargain for his/her own economic interests. When engaging in business with strangers, stall-keepers and factory owners base their decisions on market rationality and market-based transactions. When relatives and friends (including hometown-fellows and former employers-employees) are involved in business transactions, the emphasis is on social obligations of mutual aid and shared economic interests. The exchange of favours and mutual economic benefit are routinely mentioned. Under typical conditions, connections between these stall-keepers and factory owners and their relatives and friends can be further extended, and this set of social relations becomes the foundation for a business network. The daily interactions of businesspeople (primarily men) also take the forms of offering red envelopes, playing mah-jong, or enjoying sexual services together, indicating the lack of a sharp divide between social networking and business networking. "[N]etwork building is used (consciously or unconsciously) by Chinese adults as a cultural strategy in mobilising social resources for goal attainment in various spheres of social life." (43) Business negotiation and transactions are also tightly integrated into day-to-day social life.

When family relations are incorporated into business transactions (particularly in running both wholesale and manufacturing businesses), the business is regarded as part of the material life of the family. There is no bargaining between wholesale and manufacturing businesses run by the same family because all economic returns from the businesses are considered family assets and will be used for the family's wellbeing. Furthermore, family commitment orients family members towards family welfare rather than individual economic interest.

The evidence in this study shows that businesspeople are fully aware of the social connections they encounter in the business world and manage to align each major type of social relation with an economic form. For example, a connection between strangers is related to market-based economy, while a connection with relatives and friends is linked to favour-based economy, and family connection to household economy. This diversity of economy frameworks indicates that the market economy is not something outside of society but a type of economy aligned with the particular social relation between strangers. As relatives, friends, hometown-fellows, and family members are not strangers, social relations between them often align with other socially-based economies, such as favour exchange or household economy. In this sense, the economies are integrated into the social spheres and social relations. Furthermore, the market economy and monetary mentality do not damage social life and ethics when they are properly matched with a certain kind of social relation. The misuse and mismatch of a particular social relation with a certain economic type may damage relations and have a negative impact on the economy.

Compared with the established concept of embeddedness, this relational approach provides a more comprehensive understanding of social relations and the critical role of the associated norms and obligations constituting economic action. In addition, the embeddedness approach tends to overlook the differentiation of social relations. More importantly, the relational approach enables us to perceive the co-existence of multiple economic forms in social life and directs our attention to the intermingling of economies. Each economic form makes its own contribution to creating wealth and distributing resources. The concept of embeddedness merely emphasises the status of the market economy rooted and constrained by social networks as well as the economic implications of social embeddedness.

IChong Gao is an assistant professor in the Department of Sociology at Hong Kong Shue Yan University.

Hong Kong Shue Yan University, Department of Sociology, 10 Wai

Tsui Crescent, Braemar Hill, North Point, Hong Kong

(cgao@hksyu.edu).

I Khun Eng Kuah-Pearce is professor and head of the School of Arts and Social Sciences at Monash University, Malaysia Campus. Monash University Malaysia, School of Arts and Social Sciences, Jalan Lagoon Selatan, 47500 Bandar Sunway, Selangor Darul Ehsan, Malaysia (kuah.khun.eng@monash.edu). 